\title{
Rearranging the deck chairs
}

\author{
Mark S. Allen, MD
}

From the Department of Surgery, Mayo Clinic, Rochester, Minn.

Disclosures: Author has nothing to disclose with regard to commercial support.

Received for publication Oct 2, 2017; accepted for publication Oct 7, 2017; available ahead of print Oct 31, 2017.

Address for reprints: Mark S. Allen, MD, Department of Surgery, Mayo Clinic, 2001 st St, SW, Rochester, MN

55902 (E-mail: Allen.mark@mayo.edu).

J Thorac Cardiovasc Surg 2018;155:1205

$0022-5223 / \$ 36.00$

Copyright (c) 2017 by The American Association for Thoracic Surgery

https://doi.org/10.1016/j.jtcvs.2017.10.019

Lung cancer remains the number one cancer killer worldwide with an estimated 1.6 million cancer fatalities in the year 2012. The article ${ }^{1}$ included in this edition of the Journal is a very well-done study by the group from Memorial Sloan Kettering. They reviewed their large experience with surgical resection of patients with lung cancer and examined 893 patients who had node-negative non-small cell lung cancer in an attempt to determine the factors that are associated with recurrence after resection.

Their findings are what we would expect, including an increased recurrence rate in patients with a higher $\mathrm{T}$ stage, lymphovascular invasion, a higher standardized uptake value on positron emission tomography scan, and certain types of histology with increased recurrence rates. It should make surgeons feel good that they also found a more recent surgical resection has a lower rate of recurrence than those of the past, implying that we are improving our surgical techniques. As the authors state, hopefully these findings will identify a subset of patients with early-stage lung cancer who are at risk for recurrence and eventually death, and may lead to discovery of new options for treatment in these patients with early-stage disease.

However, the importance of this article is limited, because only a small percentage of patients with lung cancer have early-stage disease when diagnosed. In the Surveillance, Epidemiology, and End Results database review of lung cancer from 2007 to 2013 , only $16 \%$ of patients had localized disease. The majority had involvement of lymph nodes, and approximately $60 \%$ had metastatic disease at time of presentation. Thus, trying to identify a subset of patients with node-negative disease for further therapy is much like rearranging the deck chairs on the Titanic when

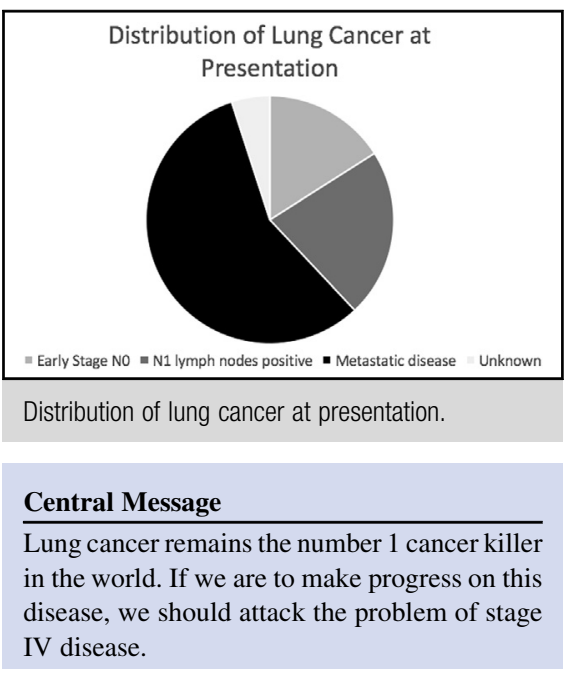

See Article page 1212.

it is sinking. The main problem with lung cancer survival is not the small set of patients who are node negative; it is the majority of patients who are not diagnosed until the disease is too far along. The mortality rate for stage IV lung cancer, as the readers of this Journal know, is approximately $100 \%$. Without efforts that address patients with stage IV disease, we will not make much progress. Despite all the research in lung cancer, the cure rate in 2003 was still a meager $15.5 \%$. This is in comparison with other cancers, such as breast, colon, or lymphoma, that have had major improvements. We should look at prevention and improved screening for earlier detection, including computed tomography screening, circulating DNA, and breath testing for volatile organic compounds to try to identify patients earlier, thus allowing surgical expertise to cure their lung cancer.

\section{Reference}

1. Brandt WS, Bouabdallah I, Tan KS, Park BJ, Adusumilli PS, Molena D, et al. Factors associated with distant recurrence following R0 lobectomy for pN0 lung adenocarcinoma. J Thorac Cardiovasc Surg. 2018;155:1212-24. 